\title{
The relationship between statistics of warm-season cloud episodes and synoptic weather regimes over the East Asian continent
}

\author{
Chung-Chieh Wang • George Tai-Jen Chen • \\ Richard E. Carbone
}

Received: 25 February 2010/Accepted: 13 January 2011/Published online: 6 April 2011

(c) Springer-Verlag 2011

\begin{abstract}
In this study, the relationship between statistical properties (including zonal span, duration, and propagation speed) of warm-season cloud episodes in Hovmöller space and synoptic conditions over the East Asian continent is investigated for the period of May-July 1997-2002. Synoptic conditions are classified into four regimes: those with baroclinity only at lower level (L), only at upper level (U), at both lower and upper levels (B), or at neither level $(\mathrm{N})$, and cloud streaks (i.e., episodes as identified through an automated procedure) in each regime are stratified based on their zonal span (length in the East-West direction). It is found that there exists a tendency for episodes in regime $\mathrm{B}$ to be larger than episodes in regime N. For larger and less frequent episodes with a zonal span more than about $1,400 \mathrm{~km}$, low-level conditions appear to have slightly higher importance than upper-level conditions, as streaks in regime $\mathrm{L}$ tend to be larger than those in regime U. Overall, the results point to the possibility that both upper-level steering and low-level features are important for major episodes that propagate at the leeside of the Tibetan Plateau for long distances across the East Asian continent.
\end{abstract}

Responsible Editor: L. Gimeno.

C.-C. Wang

Department of Earth Sciences, National Taiwan Normal

University, Taipei, Taiwan, Republic of China

G. T.-J. Chen $(\square)$

Department of Atmospheric Sciences, National Taiwan

University, No. 61, Ln. 144, Sec. 4, Keelung Rd,

Taipei 10772, Taiwan, Republic of China

e-mail: george@as.ntu.edu.tw

\section{R. E. Carbone}

National Center for Atmospheric Research, Boulder, Colorado, USA
A better understanding of the episode behavior in the area is important for future application to improve the quantitative precipitation forecasts in warm season.

\section{Introduction}

Based on high-resolution ( $2 \mathrm{~km}$ in space and $15 \mathrm{~min}$ in time) radar data, Carbone et al. (2002) found that warmseason precipitation episodes, defined as clusters of rainproducing systems in Hovmöller (longitude-time) space, in the continental United States (US) exhibit characteristics of propagation at the speed range of $10-25 \mathrm{~m} \mathrm{~s}^{-1}$. The longevity of some episodes in space (at the zonal direction, specifically) and time, up to $3,000 \mathrm{~km}$ and $60 \mathrm{~h}$, suggests the existence of an intrinsic predictability and thus the potential for improvements in quantitative precipitation forecast (QPF) at lead times over the range of 6-48 h (Fritsch and Carbone 2004). For East Asia, Wang et al. (2004) used the Geostationary Meteorological Satellite (GMS) infrared (IR) blackbody brightness temperature $\left(T_{\mathrm{BB}}\right)$ data and found similar properties in cloud episodes to the lee of the Tibetan Plateau (TP), particularly in early summer (May-June), with event scales up to 2,500 km and $40 \mathrm{~h}$. Several recent studies of rainfall episodes in other parts of the world also showed coherent behavior of propagation, eastward in mid-latitudes/subtropics and westward in the tropics, including Laing et al. (2008) for Africa, Keenan and Carbone (2008) for Australia and the maritime continent, Levizzani et al. (2010) for Europe and the Mediterranean, Pereira et al. (2010) for South America, and Liu et al. (2008) for the Bay of Bengal.

An important property of these precipitation/cloud episodes lies in their close ties to the diurnal cycle of major elevated terrain (Carbone et al. 2002, 2005; Wang et al. 

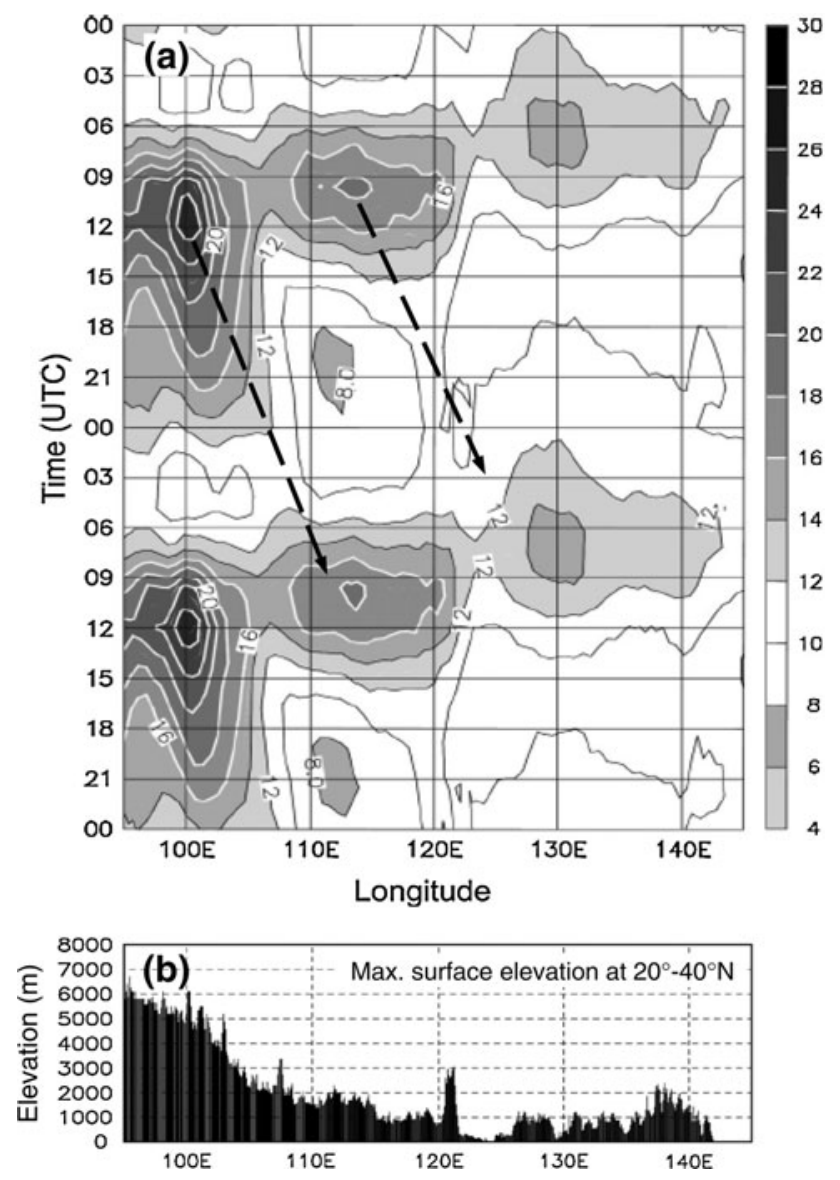

Fig. 1 a Hovmöller diagram of mean diurnal cycle of N-S averaged cold cloud frequency $\left(T_{\mathrm{BB}} \leq-32^{\circ} \mathrm{C}, \%\right)$ in East Asia $\left(20-40^{\circ} \mathrm{N}\right.$, $\left.95-145^{\circ} \mathrm{E}\right)$ during May-August, $1998-2001$ and $\mathbf{b}$ maximum surface elevation $(\mathrm{m})$ in the $\mathrm{N}-\mathrm{S}$ direction within the domain. The cycle is repeated twice for clarity, and dash arrows indicate eastward propagation of signals in a. (adapted from Wang et al. 2004)

2004, 2005). As illustrated in Fig. 1, East Asian episodes tend to develop over the eastern TP near local dusk (1100 UTC or $1800 \mathrm{LST}$ at $105^{\circ} \mathrm{E}$ ) then propagate eastward overnight, sometimes into the next day (cf. Fig. 2). The high terrain and its eastern slope act as the heat source to trigger deep convection (e.g., Holton 1968; Wallace 1975; Ahijevych et al. 2004; Huang et al. 2010), often on a daily basis, and subsequent downstream propagation tends to occur when strong upper-level steering winds are present in a sheared environment, sometimes for long distances (e.g., Rotunno et al. 1988). In the US, the nocturnal propagation of organized convection across the Great Plains is well known (e.g., Augustine and Howard 1991; Laing and Fritsch 1997; Davis et al. 2003), and such events may account for a sizeable fraction of all episodes (Carbone et al. 2005; Carbone and Tuttle 2008). In East Asia, nocturnal convection to the lee of the plateau near the Sichuan Basin (SB, cf. Fig. 2) has been previously noted (e.g., Asai et al. 1998), and the eastward shift in peaking time of summer rainfall along the Yangtze River Valley (YRV), from midnight at the upper reaches (i.e., over the SB area) to morning at the middle reaches than further to afternoon at the lower reaches, is recently confirmed using rain-gauge data (Yu et al. 2007; Chen et al. 2010). Several nocturnal events that produced severe floods downstream from the plateau have also been studied (e.g., Wang and Orlanski 1987; Wang et al. 1993). The rainfall events that tie to the diurnal cycle of the terrain, due to their coherency and regularity, represent an area where the improvement in warm-season QPF appears quite promising at the present time.

Although warm-season precipitation episodes occur under a variety of synoptic conditions, many of which lack significant dynamical forcing and can be described as "weakly-forced" (as opposed to cold-season conditions), they are nevertheless affected and modulated by their environment as demonstrated by many earlier studies (e.g., Wang and Orlanski 1987; Tuttle and Carbone 2004). The role played by the environment can be essential, and this is perhaps especially true in East Asia (as compared to the US) where monsoon circulations are prominent (e.g., Ding 1992). Over China, particularly, the summer monsoon typically exhibits two distinct rainy periods in its life cycle (e.g., Lau et al. 1988; Chen et al. 2004). The first occurs
Fig. 2 The domain used for Hovmöller calculation (thick solid line) and synoptic weather regime identification and classification (thick dotted line)




roughly from late-May to mid-July from the southern to central China, and is associated with frequent development of Mei-yu fronts (also Tao and Chen 1987). Following the northward migration of the subtropical high and a monsoon break, the second rainy period generally covers late-July through August and takes place over both southern and northeastern China (and northeastern Asia). The rainfall in southern China is related to the intertropical convergence zone (ITCZ) and tropical cyclones (e.g, Lau and Li 1984; Chen et al. 2004), while that to the north is mainly attributed to midlatitude frontal activities (e.g., Lau et al. 1988; Chen et al. 2004). To the lee of the TP (over southerncentral China), Mei-yu fronts therefore often provide some forcing of varying degree throughout May to July, i.e., during the first summer monsoon rainy period (e.g., Chen 1993; Chen et al. 2003). Thus, it is expected that some synoptic conditions in the environment favor more organized, longer-lived episodes to occur, while others tend to suppress the larger events. Such investigation on synoptic conditions is not only helpful for understanding the behavior of episodes, but also essential for a more successful application of their statistical properties in QPF as an aid to model prediction (e.g., Fritsch and Carbone 2004). As a first effort, the present study therefore examines this relationship through a comparison of statistical properties of episodes (or streaks) under different synoptic weather regimes, using a cloud-streak data base extended from Wang et al. (2004).

The remaining part of this paper is arranged in the following manner. The data and methodology are described in Sect. 2, and the results of weather regime classification are discussed in Sect. 3. The statistical relationship between episodes and synoptic weather regimes are presented in Sect. 4, while Sect. 5 is devoted to the discussion and conclusion.

\section{Data and methodology}

The set of cloud streaks (referred to here as the episodes identified through the automated procedure to be described) used in the present study is the same as that in Wang et al. (2004), except that the data period is extended to 1997-2002 (from 1998-2001). As reviewed in Sect. 1, since the rainfall over southern-central China is mainly caused by tropical systems and the propagation of rainfall episodes to the lee of the TP nearly ceases in mid-summer when the westerly flow shifts north (Wang et al. 2004, 2005), all events in August are excluded from our analysis. The methodology to identify the streaks and obtain their statistics is detailed by Wang et al. (2004) and described briefly below. The computational domain of $20-40^{\circ} \mathrm{N}$ and $95-145^{\circ} \mathrm{E}$ (Fig. 2) was first divided into narrow N-S strips of $0.1^{\circ}$ wide in longitude, and $T_{\mathrm{BB}}$ values (at $5-\mathrm{km}$ and $1-\mathrm{h}$ resolutions) were averaged within each strip. Using time as the second dimension, data were thus aggregated into longitude-time (Hovmöller) space. To remedy the problem caused by rising background temperature from May to July and also to emphasize deeper, colder clouds, $T_{\mathrm{BB}}>0^{\circ} \mathrm{C}$ were replaced by $0^{\circ} \mathrm{C}$ before averaging. Then, cloud streaks were identified through a two-dimensional (2D) rectangular autocorrelation function $\left(4^{\circ}\right.$ longitude $\times 8 \mathrm{~h}$ in size). The function is weighted evenly in one direction and by a negative cosine curve in the other, and by rotating it on each point in the Hovmöller space until the coefficient is maximized, data orientation can be identified (Wang et al. 2004). A "fit" was recorded if the coefficient reached 0.4 at a given point, while streaks were recognized by fits at contiguous points. Using this procedure, endpoints of cloud streaks were identified and their statistics (zonal span, duration, and mean propagation speed) were obtained.

For the classification of synoptic regimes, the Japan Meteorological Agency (JMA) daily weather maps at 0000 UTC at the mean sea level (MSL), 850, 500, and $300 \mathrm{hPa}$ were used. Since our main interests were over the continent where episode propagation is more frequent and pronounced (Wang et al. 2005), weather systems linked to baroclinity inside $24-36^{\circ} \mathrm{N}, 100-125^{\circ} \mathrm{E}$ (cf. Fig. 2) were identified through visual inspection and used to classify the data period into four mutually exclusive regimes with criteria listed in Table 1: (1) the low-level regime (L regime) where a front or a low pressure system with central pressure $<1,000 \mathrm{hPa}$ existed at the surface (i.e., MSL), or strong horizontal wind shear or a southwesterly low-level jet (LLJ, $\geq 12.5 \mathrm{~m} \mathrm{~s}^{-1}$ ) appeared at $850 \mathrm{hPa}$; (2) the upperlevel regime (U regime) where a closed low or a trough with clear $v$-components, or strong southwesterly flow of $\geq 15 \mathrm{~m} \mathrm{~s}^{-1}$ ahead of a trough existed at $500 \mathrm{hPa}$, or a trough appeared at both 500 and $300 \mathrm{hPa}$; (3) the both

Table 1 Criteria used for synoptic weather regime classification in the present study

\begin{tabular}{|c|c|}
\hline Weather regimes & Criteria of classification \\
\hline \multirow[t]{3}{*}{ L: Low-level } & Front or low $<1,000 \mathrm{hPa}$ at surface (MSL), or \\
\hline & $\begin{array}{l}\text { Horizontal wind shear } \geq 12.5 \mathrm{~m} \mathrm{~s}^{-1} \text { across } \\
\text { shear zone at } 850 \mathrm{hPa} \text {, or }\end{array}$ \\
\hline & Southwesterly LLJ $\geq 12.5 \mathrm{~m} \mathrm{~s}^{-1}$ at $850 \mathrm{hPa}$ \\
\hline \multirow[t]{3}{*}{ U: Upper-level } & $\begin{array}{l}\text { Closed low or trough with } v \text {-wind } \geq 7.5 \mathrm{~m} \mathrm{~s}^{-1} \\
\text { at } 500 \mathrm{hPa} \text {, or }\end{array}$ \\
\hline & $\begin{array}{l}\text { Southwesterly flow } \geq 15 \mathrm{~m} \mathrm{~s}^{-1} \text { ahead of } \\
\text { trough at } 500 \mathrm{hPa} \text {, or }\end{array}$ \\
\hline & Trough at both 500 and $300 \mathrm{hPa}$ \\
\hline $\begin{array}{l}\text { B: Both lower- and } \\
\text { upper-levels }\end{array}$ & Both criteria of L- and U-regimes are met \\
\hline $\mathrm{N}$ : Neither level & Neither criteria of L- nor U-regime is met \\
\hline
\end{tabular}


regime (B regime) where the criteria for both lower- and upper-level systems were met; and (4) the no regime (N regime) where neither lower- nor upper-level system existed (Table 1). Note that in the B regime, favorable conditions existed at both lower and upper levels, but they are not necessarily dynamically coupled since the identification is independent. Likewise, although manual checks for selected periods reveal that the weather systems identified to the lee of the TP were often associated with widespread convection, there is no guarantee that a close link always exists between them that occur nearby. In fact, during this procedure, such identification of synoptic weather regimes should be kept strictly independent from that of cloud streaks, so that no bias is introduced.

After the daily weather regimes were classified, all eastward-moving cloud streaks identified were then categorized according to the regime at the date of their midpoint in the Hovmöller space. All streaks that originated east of $125^{\circ} \mathrm{E}$ or centered east of $130^{\circ} \mathrm{E}$ were excluded, as they were outside the area of interest. Cases that moved westward were similarly omitted so that tropical influences during May-July were also eliminated.

\section{Weather regime classification}

Using the described method, the synoptic regimes in the order of N, L, U, and B occurred roughly $26,36,11$, and $26 \%$ of the times during our data period, while the remaining $1 \%$ was not classified since $T_{\mathrm{BB}}$ data were missing (Fig. 3a). Days in regime B were almost twice more frequent in May-June than in July $(114 / 366=31.1 \%$ vs. $29 / 186=15.6 \%$ ). On the contrary, there were fewer days in regime $\mathrm{L}$ in May $(51 / 186=27.4 \%)$ than in JuneJuly $(150 / 366=41.0 \%)$, when slow-moving Mei-yu fronts often appeared near $30^{\circ} \mathrm{N}$ (e.g., Tao and Chen 1987; Ding 1992). Consequently, days with no system (regime N) were the fewest in June (12.8\%) but more in May and July (25.3 and $39.2 \%)$. Regime $\mathrm{U}$ was the least frequent $(10.5 \%)$ of all regimes with the majority occurring in May (33 days, Fig. 3a). The above results of the intra-seasonal variation in the frequencies of regimes $\mathrm{B}, \mathrm{L}, \mathrm{U}$, and $\mathrm{N}$ are in general agreement with the gradual northward migration of the subtropical high and the baroclinic zone (e.g., Lau et al. 1988; Chen et al. 2004).

Among a total of 2,505 all eastward-moving cloud streaks, without considering their span and duration, the largest fraction occurred in regime $\mathrm{L}(38.7 \%)$ followed by regime $\mathrm{N}(25.9 \%), \mathrm{B}(25.7 \%)$, and $\mathrm{U}(9.7 \%$, Fig. 3b), roughly in proportion to the number of days in each regime, except for July where streaks in regime $\mathrm{N}$ were relatively few. When only the 1,794 streaks at least $3 \mathrm{~h}$ in duration were considered (Fig. 3c), the percentages rose
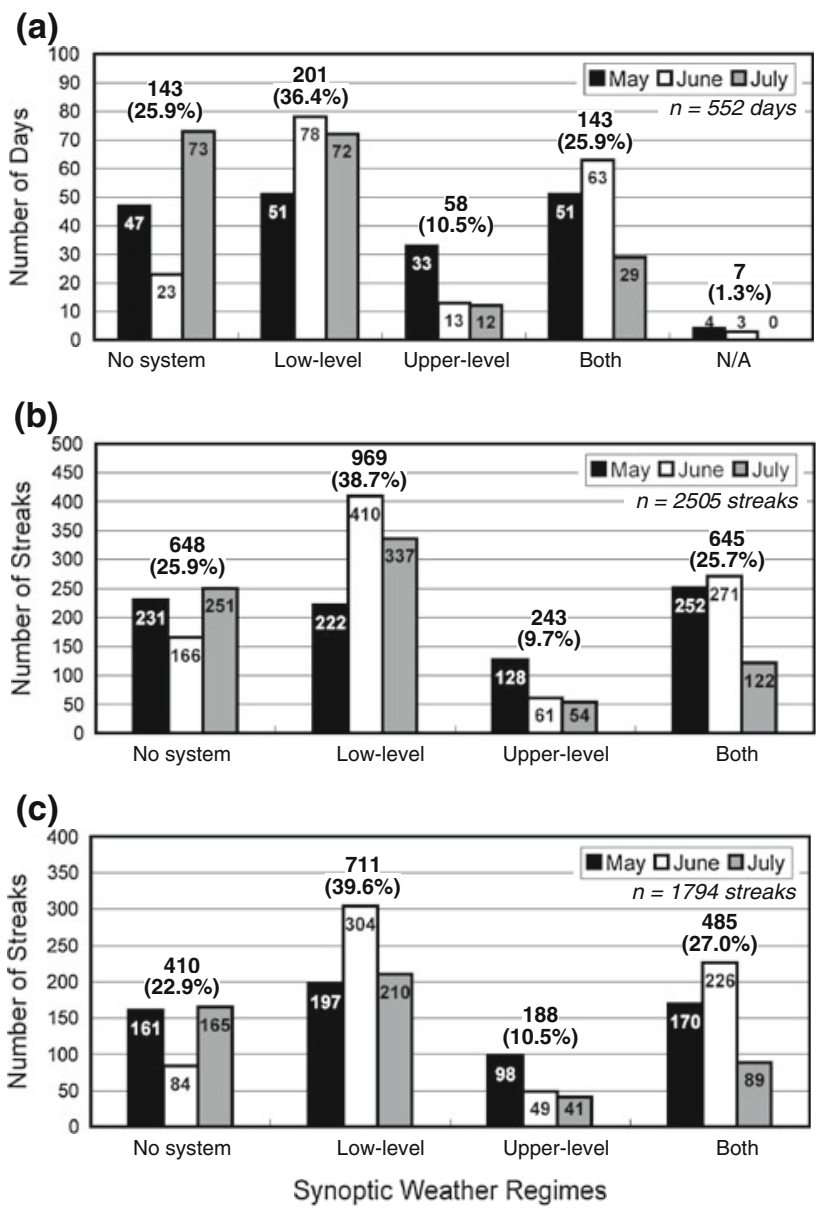

Fig. 3 Distribution of a number of days $(n=552)$, b number of all cloud streaks $(n=2,505)$, and $\mathbf{c}$ number of all cloud streaks $\geq 3 \mathrm{~h}$ ( $n=1,794$ ) by month (May-July) in each synoptic regime. Days with missing $T_{\mathrm{BB}}$ data were grouped as N/A in a

slightly in regimes $\mathrm{L}, \mathrm{U}$, and $\mathrm{B}$ (by about $1 \%$ ) but dropped in regime $\mathrm{N}$ (by 3\%). The difference in Fig. 3b, c indicated only a slightly higher percentage of short-lived streaks (i.e., those $<3 \mathrm{~h}$ ) in regime $\mathrm{N}$ compared to other regimes, and the relationship between synoptic regimes and the number of cloud streaks is apparently weak when the streaks are not stratified according to their size.

\section{Statistical relationship between episodes and synoptic regimes}

The relationship between cloud streaks and synoptic regimes is further examined in Table 2, where the 1974 eastward-moving streaks $\geq 3 \mathrm{~h}$ are stratified by means of recurrence frequency. The recurrence frequency is defined as the averaged time interval for events of a certain magnitude (or size) to reoccur. For example, regime $\mathrm{N}$ had 143 days and 410 cases (Table 2), and thus at the frequency of one per day, the table gives the size of the 143rd 
Table 2 Zonal span (km, top) and duration (h, bottom) of all eastward-moving cloud streaks at least $3 \mathrm{~h}$ in duration, stratified by recurrence frequency, under different synoptic regime $(\mathrm{N}, \mathrm{L}, \mathrm{U}$, and B) during May-July, 1997-2002

\begin{tabular}{llllll}
\hline $\begin{array}{l}\text { Recurrence } \\
\text { frequency }\end{array}$ & \multicolumn{5}{l}{ Zonal span and duration } \\
\cline { 2 - 6 } & $\mathrm{N}(410)$ & $\mathrm{L}(711)$ & $\mathrm{U}(188)$ & $\mathrm{B}(485)$ & All (1794) \\
\hline 1 per day & 404 & 525 & 525 & 539 & 501 \\
& 8.0 & 10.0 & 10.0 & 10.0 & 9.5 \\
1 per 2 days & 665 & 925 & 1,011 & 997 & 876 \\
& 12.0 & 16.0 & 16.0 & 16.0 & 15.5 \\
2 per day & 1,045 & 1,329 & 1,368 & 1,449 & 1,262 \\
& 17.0 & 21.0 & 20.0 & 22.5 & 20.0 \\
1 per week & 1,392 & 1,767 & 1,647 & 1,974 & 1,714 \\
& 22.0 & 27.5 & 28.0 & 31.5 & 27.5 \\
2 per month & 1,767 & 2,436 & 2,172 & 2,663 & 2,398 \\
& 28.0 & 34.0 & 37.0 & 39.0 & 36.0 \\
1 per month & 2,383 & 2,855 & 2,528 & 3,390 & 2,831 \\
& 32.5 & 41.0 & 39.5 & 47.5 & 41.0 \\
\hline
\end{tabular}

The total numbers of streaks are given in parentheses

largest case $(404 \mathrm{~km}$ and $8 \mathrm{~h}$ ) out of all 410 ones. In regime $\mathrm{B}$, values of zonal span and duration at various recurrence frequencies were all largest among all regimes, except for span at 1 per 2 days (Table 2). On the contrary, streaks in regime $\mathrm{N}$ had the smallest thresholds at all frequencies, since no favorable system existed to help organize the convection into episodes of longer duration. Thus, Table 2 suggests that synoptic forcing at both low level and aloft (over deep layers for most cases) was helpful for the propagation of cloud streaks. Regime L contained the most days and streaks (201 and 711) and the cut-off values at 1 per day and 1 per 2 days were quite comparable to those in regime $\mathrm{B}$ (Table 2). For large episodes fewer than once a week, thresholds in regime $\mathrm{L}$ were also the second largest among all categories. Regime U, though the least frequent (58 days and 188 cases), was also quite favorable for events about several hundred to $1,400 \mathrm{~km}$ in span. For episodes at low recurrence frequency (i.e., those with larger span and longer duration), however, the values in Regime $\mathrm{U}$ became increasingly smaller than those in regime $\mathrm{B}$ (Table 2). This suggests that upper-level troughs with their forcing alone were helpful for streaks to grow into moderate size, but low-level conditions tended to play an increasingly more important role if very large episodes were to develop.

The scatter plots of zonal span versus duration for eastward-moving streaks $\geq 3 \mathrm{~h}$ (Fig. 4) also indicated that there were greater numbers of large events in regimes $\mathrm{B}$ (a) Cloud Streaks May-August 1997-2002 (Weather Regime N)



(c)

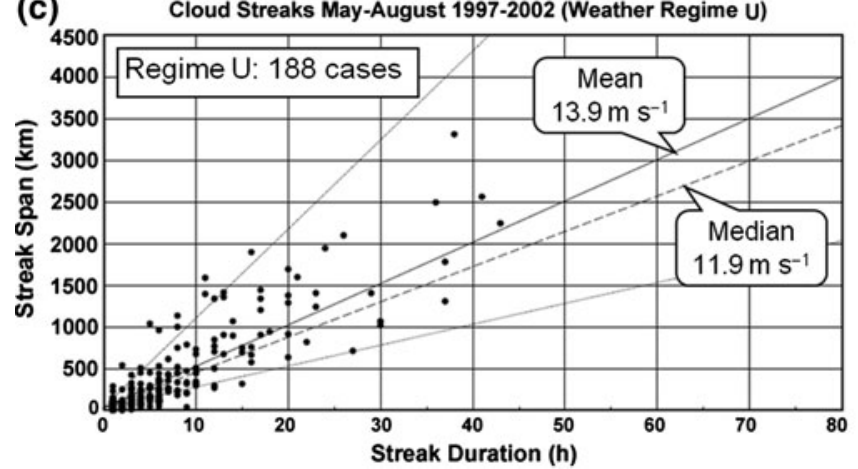

(b)

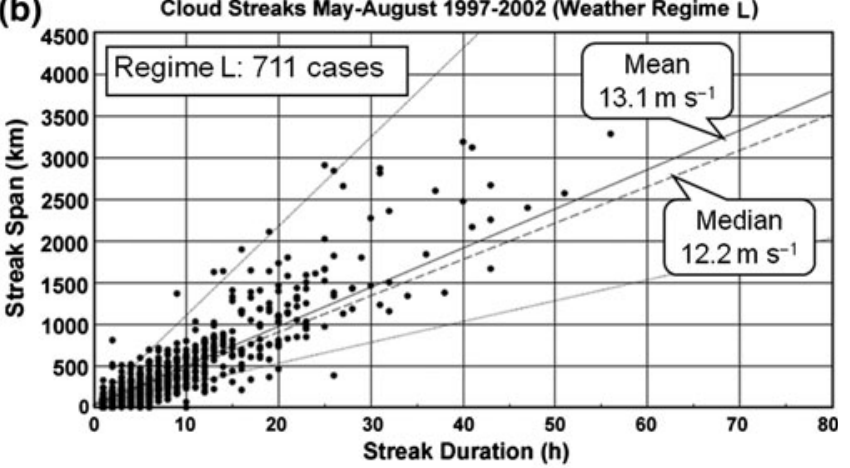

(d) Cloud Streaks May-August 1997-2002 (Weather Regime B)

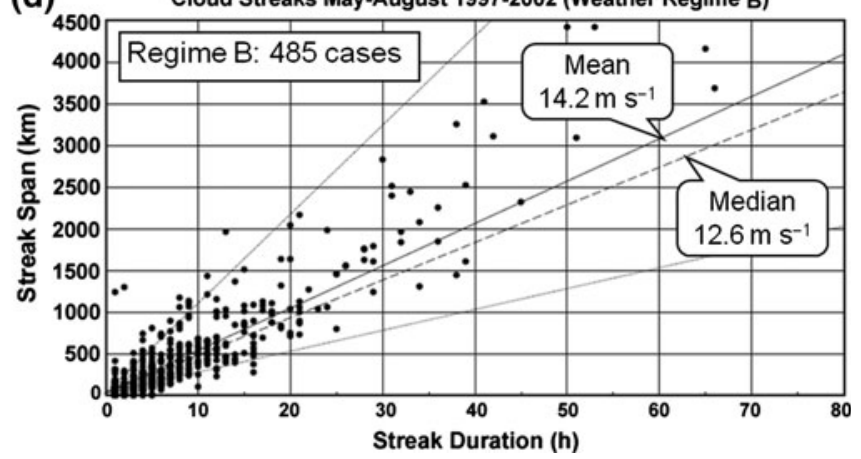

Fig. 4 Scatter splots of zonal span versus duration of all streaks $\geq 3 \mathrm{~h}$ in each of the four synoptic weather regimes: $\mathbf{a} \mathrm{N}$ regime, $\mathbf{b} \mathrm{L}$ regime, $\mathbf{c} \mathrm{U}$ regime, and $\mathbf{d} \mathrm{B}$ regime. The mean and median speeds of all streaks in each category are indicated, and dotted lines correspond to 7 and $30 \mathrm{~m} \mathrm{~s}$ 


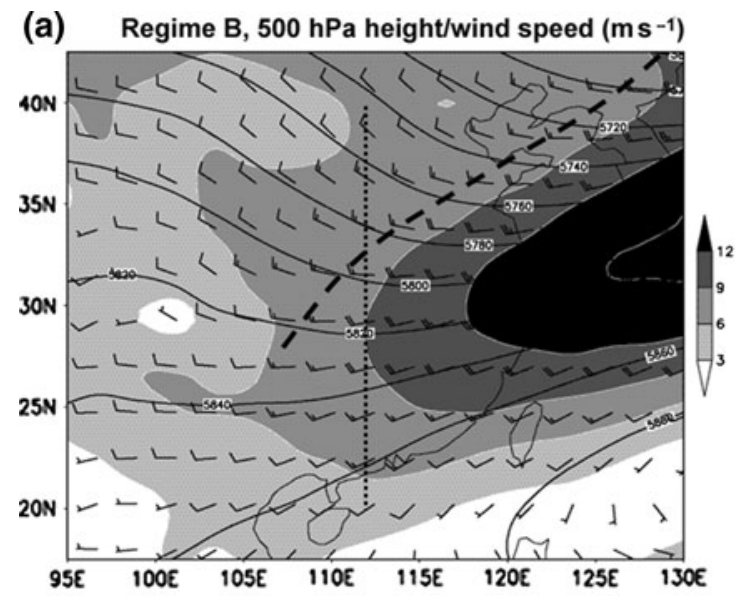

(c) Regime $\mathrm{B}, 850 \mathrm{hPa}$ height/conv $\left(10^{-5} \mathrm{~s}^{-1}\right)$



Fig. 5 Composite a 500-hPa geopotential height (gpm, contours) and winds $\left(\mathrm{m} \mathrm{s}^{-1}\right.$, half barbs for $2.5 \mathrm{~m} \mathrm{~s}^{-1}$ and full barbs for $5 \mathrm{~m} \mathrm{~s}^{-1}$, speed shaded) and c $850-\mathrm{hPa}$ geopotential height, winds, and convergence $\left(10^{-5} \mathrm{~s}^{-1}\right.$, shaded $)$ in regime B. b, d Same as a, c but

and then L (say, for episodes with span $>1,500 \mathrm{~km}$ or duration $>30 \mathrm{~h}$ ), and these streaks tended to travel at a speed of about $17-20 \mathrm{~m} \mathrm{~s}^{-1}$, slightly faster than both the mean (13-14 $\mathrm{m} \mathrm{s}^{-1}$ ) and median speed (about $12.5 \mathrm{~m} \mathrm{~s}^{-1}$ ) of all events sampled in each regime (Fig. 4b, d). Regimes $\mathrm{N}$ and $\mathrm{U}$ (Fig. $4 \mathrm{a}, \mathrm{c}$ ), on the other hand, contained relatively fewer large streaks. However, a small fraction of the cloud streaks in the latter two categories could still reach about $2,500 \mathrm{~km}$ and $36 \mathrm{~h}$, i.e., develop under weakly forced conditions, similar to the result of Carbone et al. (2002).

\section{Discussion and conclusion}

Results in Sects. 3 and 4 investigate only the statistical properties of cloud episodes in relation to synoptic-scale weather regimes over the East Asian continent. To further make physical links, the European Centre for Mediumrange Weather Forecasts (ECMWF) gridded analyses at
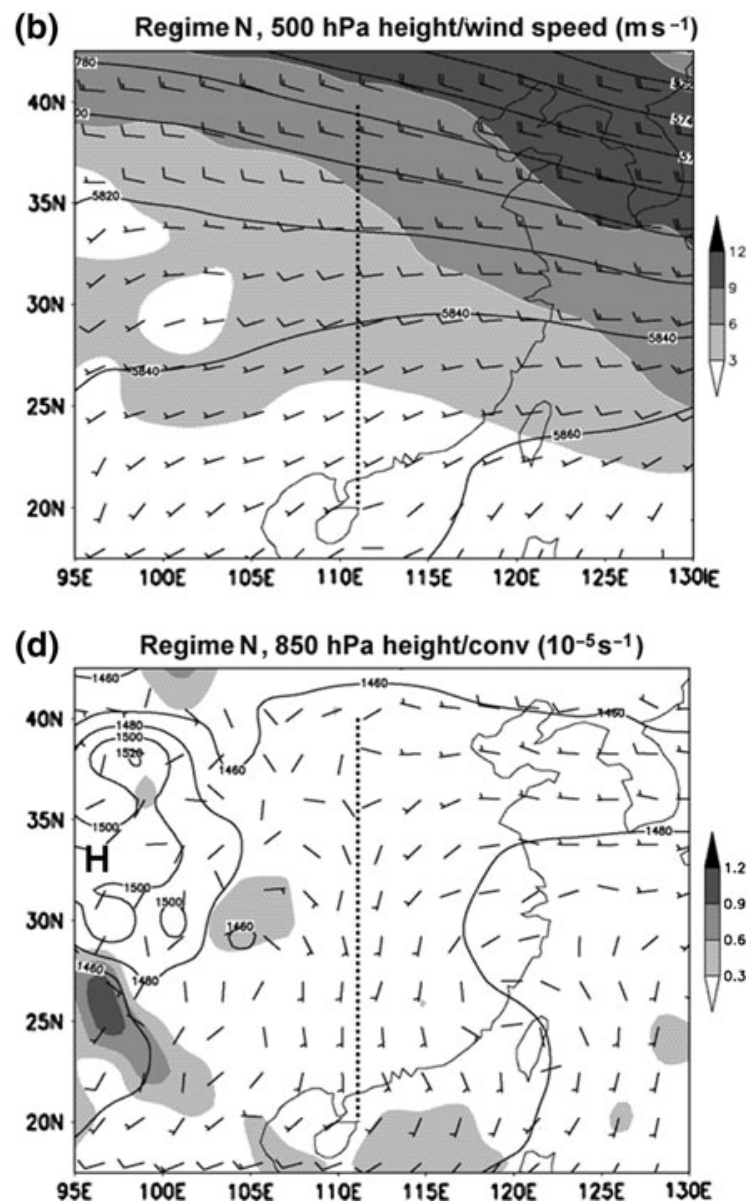

in regime N. Thick dashed lines indicate the trough or wind shear line, and dotted lines mark the mean zonal position at the mid-point of all cloud streaks $\geq 3 \mathrm{~h}$ (in the Hovmöller domain, at $20-40^{\circ} \mathrm{N}$ ) in association with the particular weather regime

$1.125^{\circ}$ latitude/longitude resolution at 0000 UTC during the data period were used to produce composites for each regime. The 500-hPa pattern for regime B (Fig. 5a) shows a confluent trough approaching our domain of interest $\left(24-36^{\circ} \mathrm{N}, 100-125^{\circ} \mathrm{E}\right)$, and close to the averaged midpoint position of all eastward-moving cloud streaks $\geq 3 \mathrm{~h}$. The trough has an east-northeast-west-southwest orientation with west-northwesterly flow behind, and the wind speeds ahead of it, over eastern China, are about 5-14 $\mathrm{m} \mathrm{s}^{-1}$. A similar trough did not exist, and both the height gradient and wind speed were much weaker in the composite for regime $\mathrm{N}$ (Fig. 5b). Thus, the (mean) cyclonic vorticity advection and the associated divergence at upper levels in regime B (e.g, Bluestein 1993, Sec. 5.7; Doswell and Bosart 2001) produce synoptic-scale upward motion beneficial for convection development and maintenance. The baroclinity and vertical westerly wind shear, likewise, are both significantly stronger in regime B than regime $\mathrm{N}$, and such sheared environment is more prone to the maintenance and propagation of rain-producing 
systems (e.g., Rotunno et al. 1988, Doswell 2001). At $850 \mathrm{hPa}$, a closed low and a clear wind shear line also appear near the Yangtze River Valley along $30^{\circ} \mathrm{N}$ in the composite (thick dashed) for regime $\mathrm{B}$, with strong southwesterly winds $\geq 15 \mathrm{~m} \mathrm{~s}^{-1}$ and convergence exceeding $0.3 \times 10^{-4} \mathrm{~s}^{-1}$ (Fig. 5c). These weather features are reminiscent of those associated with Mei-yu fronts during the first active period of the summer monsoon in the region (e.g., Lau et al. 1988; Chen et al. 2004), and can provide a means to trigger and organize convection (e.g. Chen et al. 2003, 2008) and to further transport and supply moisture from the South China Sea (e.g., Chen and Chen 1995). In the composite at $850 \mathrm{hPa}$ for regime $\mathrm{N}$, a similar shear line does not exist and the flow is mainly from the south and much weaker (Fig. 5d). In the study by Trier et al. (2006), the authors also found that both the low-level frontal zone and LLJ were important for the maintenance of several long-lived nocturnal propagating episodes over the central US. For regime U, the composites at 500 and $850 \mathrm{hPa}$ were similar to Fig. 5a, d, while they were similar to Fig. 5b, c for regime L. Thus, these composites are not shown here.

In the present work, the warm-season cloud episodes over the East Asia, identified by Wang et al. (2004) using GMS IR $T_{\mathrm{BB}}$ data and extended for the period of May-July 1997-2002, were studied. Through the use of JMA weather maps and the criteria listed in Table 1 , daily synoptic conditions for the domain of $24-36^{\circ} \mathrm{N}, 100-125^{\circ} \mathrm{E}$ during the data period were classified into four mutually exclusive types based on the presence of baroclinity at different levels: Regime L where weather systems favorable for convection existed only at low levels; regime $U$ where systems were present only at upper levels; regime B where criteria for both regimes $\mathrm{L}$ and $\mathrm{U}$ were met; and regime $\mathrm{N}$ where no system was present at either lower or upper troposphere. The dependency of episodes (streaks) on weather regimes was examined from a statistical standpoint, and discussed through the use of composited ECMWF analyses.

When cloud streaks were stratified based on their size, a tendency existed for episodes to be larger under regime $\mathrm{B}$ and smaller under regime $\mathrm{N}$, as expected. Thus, conditions were most favorable when significant synoptic systems existed at both upper and lower levels through the troposphere in regime B, which occurred about $26 \%$ of the time and more in May and June. In contrast, conditions were least favorable with no significant system in regime $\mathrm{N}$ (also about $26 \%$ and less frequent in June). When regimes $\mathrm{L}$ and $\mathrm{U}$ were compared, favorable conditions at low levels appeared to be slightly more important relative to those at upper levels for larger events exceeding about $1,400 \mathrm{~km}$. Overall, the results point to the possibility that both upperlevel forcing and steering, as well as low-level features are important for major episodes that propagate for long distances across the East Asian continent.
Through a straightforward comparison of statistical properties of episodes (or streaks) associated with different synoptic weather regimes, the present study is able to show that the environment does affect cloud/precipitation episodes in an averaged sense. While a better understanding of the behavior of the episodes is important for future application to improve warm-season QPFs, a different approach must be taken in order to explore further the impact of environmental conditions (collectively or in individual events) since the statistics cannot provide information on physical processes underlying the behavior of episodes. Such an effort is already underway where we examine the commonly observed synoptic flow patterns in association with episodes that propagated for long distances, as well as those accompanying short-lived events, and the results will be reported later in a separate paper.

Acknowledgments Stimulating discussions with Drs. Stan Trier, John Tuttle, and Mitch Moncrieff during the first and second authors' visit to MMM/NCAR, as well as the comments from the reviewers are greatly appreciated. The current study is supported by the National Science Council of Taiwan, under grants NSC-99-2111-M-003-004MY3, NSC-99-2111-M-002-001, and NSC-99-2625-M-003-003.

\section{References}

Ahijevych DA, Davis CA, Carbone RE, Tuttle JD (2004) Initiation of precipitation episodes relative to elevated terrain. J Atmos Sci 61:2763-2769

Asai T, Ke S, Kodama YM (1998) Diurnal variability of cloudiness over East Asia and the Western Pacific Ocean as revealed by GMS during the warm season. J Meteor Soc Japan 76:675-684

Augustine JA, Howard KW (1991) Mesoscale convective complexes over the United States during 1986 and 1987. Mon Wea Rev 119:1575-1589

Bluestein HB (1993) Synoptic-dynamic meteorology in midlatitudes. Principles of kinematics and dynamics. vol 1. Oxford Press, New York, p 431

Carbone RE, Tuttle JD (2008) Rainfall occurrence in the U.S. warm season: the diurnal cycle. J Climate 21:4132-4146

Carbone RE, Tuttle JD, Ahijevych D, Trier SB (2002) Inferences of predictability associated with warm season precipitation episodes. J Atmos Sci 59:2033-2056

Carbone RE, Laing A, Keenan TD, Wang CC, Chen GTJ (2005) Conditions associated with warm season rainfall over Africa, Australia, China and the United States. Program and abstract book. The Fifth International Scientific Conference on the global energy and water cycle, Costa Mesa, p 256

Chen YL (1993) Some synoptic-scale aspects of surface fronts over southern China during TAMEX. Mon Wea Rev 121:50-64

Chen XA, Chen YL (1995) Development of low-level jets during TAMEX. Mon Wea Rev 123:1695-1719

Chen GTJ, Wang CC, Liu SCS (2003) Potential vorticity diagnostics of a Mei-Yu front case. Mon Wea Rev 131:2680-2696

Chen TC, Wang SY, Huang WR, Yen MC (2004) Variation of the East Asian summer monsoon rainfall. J Climate 17:744-762

Chen GTJ, Wang CC, Chang SW (2008) A diagnostic case study of Mei-yu frontogenesis and development of wavelike frontal disturbances in the subtropical environment. Mon Wea Rev 136:41-61 
Chen H, Yu R, Li J, Yuan W, Zhou T (2010) Why nocturnal longduration rainfall presents an eastward-delayed diurnal phase of rainfall down the Yangtze River Valley. J Climate 23:905-917

Davis CA, Manning KW, Carbone RE, Trier SB, Tuttle JD (2003) Coherence of warm-season continental rainfall in numerical weather prediction models. Mon Wea Rev 131:2667-2679

Ding YH (1992) Summer monsoon rainfalls in China. J Meteor Soc Japan 70:373-396

Doswell CA III (2001) Severe convective storms-an overview. Severe convective storms, Meteor Monogr No. 28, Amer Meteor Soc, pp 1-26

Doswell CA III, Bosart LF (2001) Extratropical synoptic-scale processes and severe convection. Severe Convective Storms, Meteor Monogr No. 28, Amer Meteor Soc, pp 27-69

Fritsch JM, Carbone RE (2004) Improving quantitative precipitation forecasts in the warm season. A USWRP research and development strategy. Bull Amer Meteor Soc 85:955-965

Holton JR (1968) The diurnal boundary layer wind oscillation above sloping terrain. Tellus 19:199-205

Huang HL, Wang CC, Chen GTJ, Carbone RE (2010) The role of diurnal solenoidal circulation on propagating rainfall episodes near the eastern Tibetan Plateau. Mon Wea Rev 138:2975-2989

Keenan TD, Carbone RE (2008) Propagation and diurnal evolution of warm season cloudiness in the Australian and maritime continent region. Mon Wea Rev 136:973-994

Laing AG, Fritsch JM (1997) The global population of mesoscale convective complexes. Quart J Roy Meteor Soc 123:389-405

Laing AG, Carbone RE, Levizzani V, Tuttle JD (2008) The propagation and diurnal cycles of deep convection in northern tropical Africa. Quart J Roy Meteor Soc 134:93-109

Lau KM, Li M (1984) The monsoon of East Asia and its global associations-a survey. Bull Amer Meteor Soc 65:114-125

Lau KM, Yang GJ, Shen SH (1988) Seasonal and intraseasonal climatology of summer monsoon rainfall over East Asia. Mon Wea Rev 116:18-37

Levizzani V, Pinelli F, Pasqui M, Melani S, Laing AG, Carbone RE (2010) A 10-year climatology of warm season cloud patterns over Europe and the Mediterranean from Meteosat IR observations. Atmos Res 97(4):555-576
Liu C, Moncrieff MW, Tuttle JD (2008) A note on propagating rainfall episodes over the Bay of Bengal. Quart J Roy Meteor Soc 134:787-792

Pereira AJ, Carbone RE, Janowiak JE, Arkin P, Joyce R, Hallak R, Ramos CGM (2010) Satellite rainfall estimates over South America-possible applicability to the water management of large watersheds. J Amer Wat Res Ass 46:344-360

Rotunno R, Klemp JB, Weisman ML (1988) A theory for strong, long-lived squall lines. J Atmos Sci 45:463-485

Tao S, Chen L (1987) A review of recent research on the East Asian summer monsoon in China. In: Chang C-P, Krishnamurti TN (eds) Monsoon meteorology. Oxford University Press, London, pp 60-92

Trier SB, Davis CA, Ahijevych DA, Weisman ML, Bryan GH (2006) Mechanisms supporting long-lived episodes of propagating nocturnal convection within a 7-day WRF model simulation. J Atmos Sci 63:2437-2461

Tuttle JD, Carbone RE (2004) Coherent regeneration and the role of water vapor and shear in a long-lived convective episode. Mon Wea Rev 132:192-208

Wallace JM (1975) Diurnal variations in precipitation and thunderstorm frequency over the conterminous United States. Mon Wea Rev 103:406-419

Wang B, Orlanski I (1987) Study of a heavy rain vortex formed over the eastern flank of the Tibetan Plateau. Mon Wea Rev 115:1370-1393

Wang W, Kuo YH, Warner TT (1993) A diabatically driven mesoscale vortex in the lee of the Tibetan Plateau. Mon Wea Rev 121:2542-2561

Wang CC, Chen GTJ, Carbone RE (2004) A climatology of warmseason cloud patterns over East Asia based on GMS infrared brightness temperature observations. Mon Wea Rev 132:1606-1629

Wang CC, Chen GTJ, Carbone RE (2005) Variability of warm-season cloud episodes over East Asia based on GMS infrared brightness temperature observations. Mon Wea Rev 133:1478-1500

Yu R, Zhou T, Xiong A, Zhu Y, Li J (2007) Diurnal variations of summer precipitation over contiguous China. Geophys Res Lett 34:L01704. doi:10.1029/2006GL028129 